\title{
I 004 Relation between three-dimensional echocardiography derived left ventricular volume and MRI derived circumferential strain in patients eligible for cardiac resynchronization therapy Iris K Rüssel*, Jeroen van Dijk, J Tim Marcus, Marco JW Götte and Otto Kamp
}

Address: VU University Medical Center, Amsterdam, The Netherlands

* Corresponding author

from I th $^{\text {th }}$ Annual SCMR Scientific Sessions

Los Angeles, CA, USA. I-3 February 2008

Published: 22 October 2008

Journal of Cardiovascular Magnetic Resonance 2008, I0(SuppI I):A129 doi:I0.I I86/I532-429X-I0-SI-AI29

This abstract is available from: http://jcmr-online.com/content/I0/SI/AI29

(C) 2008 Rüssel et al; licensee BioMed Central Ltd.

\section{Introduction}

Mechanical dyssynchrony (MD) is thought to be a better predictor for response to cardiac resynchronization therapy (CRT) than electrical dyssynchrony. Several methods using either ultrasound or MRI are used to quantify MD. Theoretically, three-dimensional (3D) left ventricular (LV) volume and circumferential strain seem related, since both measures are connected to the radius ( $r$ ) of the ventricle. Failing dilated hearts become more spherical, therefore their volume is proportional to $\mathbf{r}^{3}$. Circumferential strain describes length changes in the circumference of the $\operatorname{LV}(2 \pi \mathbf{r})$ and can therefore be described as $\left(\mathbf{r}_{n}-\mathbf{r}_{1}\right) / \mathbf{r}_{1}$, where $n$ is a time point in the cardiac cycle and $\mathbf{r}_{1}$ is constant. The purpose of this study was to compare regional $\mathrm{LV}$ volume curves obtained with $3 \mathrm{D}$ ultrasound with $\mathrm{LV}$ circumferential strain curves obtained by MRI in CRT candidates, to investigate whether it is likely that quantification of LV MD will give the same results for both methods.

\section{Methods}

In thirteen patients with chronic heart failure, 3D ultrasound and tagged MRI were performed subsequently. During post-processing, regional LV volume was computed from the ultrasound images by dividing a LV cast in pie shaped segments using a central line of gravity that is moving over time. From the tagged MR images, regional circumferential strain was calculated using the harmonic phase method [1]. The first 16 segments from the standard 17-segment model [2] were used, leading to a total of 208 segments to be compared. Cross-correlations with time lags of $1 \%$ of the cardiac cycle were performed to compare the curves in corresponding LV segments. MR delayed contrast enhancement (DCE) was used to detect scar tissue. The relation between the location of DCE and the cross-correlation was explored.

\section{Results and discussion}

High correlations were found between the curves (Fig. 1), but regional differences in time delay between modalities were observed. In the septum, the volume curve was later than the strain curve by $1.8 \pm 18$ time-lags (n.s.), while in the lateral wall, the volume curve was earlier than the strain curve by $4.2 \pm 12.2$ time-lags $(p<0.01)$. The difference between the volume-strain delays in both regions was significant $(p<0.01)$. In a few segments showing predominantly positive strain (lengthening), the correlation was lower. The exclusion of these curves did not lead to better correlation (208 segments vs. 178 segments (Fig. $1): r^{2}=0.67 \pm 0.23$ vs. $r^{2}=0.68 \pm 0.22, p>0.09$ ), but did lead to lower regional differences in time delay between both methods (178 segments: strain delayed with respect to volume in both the septum and the lateral wall: septal delay: $0.2 \pm 11.7$ time-lags (n.s.), lateral delay: $3.7 \pm 8.3$ time-lags $(p<0.03)$. The difference between the delays in both regions was lowered $(p=0.05)$. A possible explanation for the discrepancy between local lengthening (positive strain) and volume could be the non-fixed center line used for calculation of regional volume. Circumferential lengthening can be caused by the counteracting opposite region in these patients. In this case, the central line of 

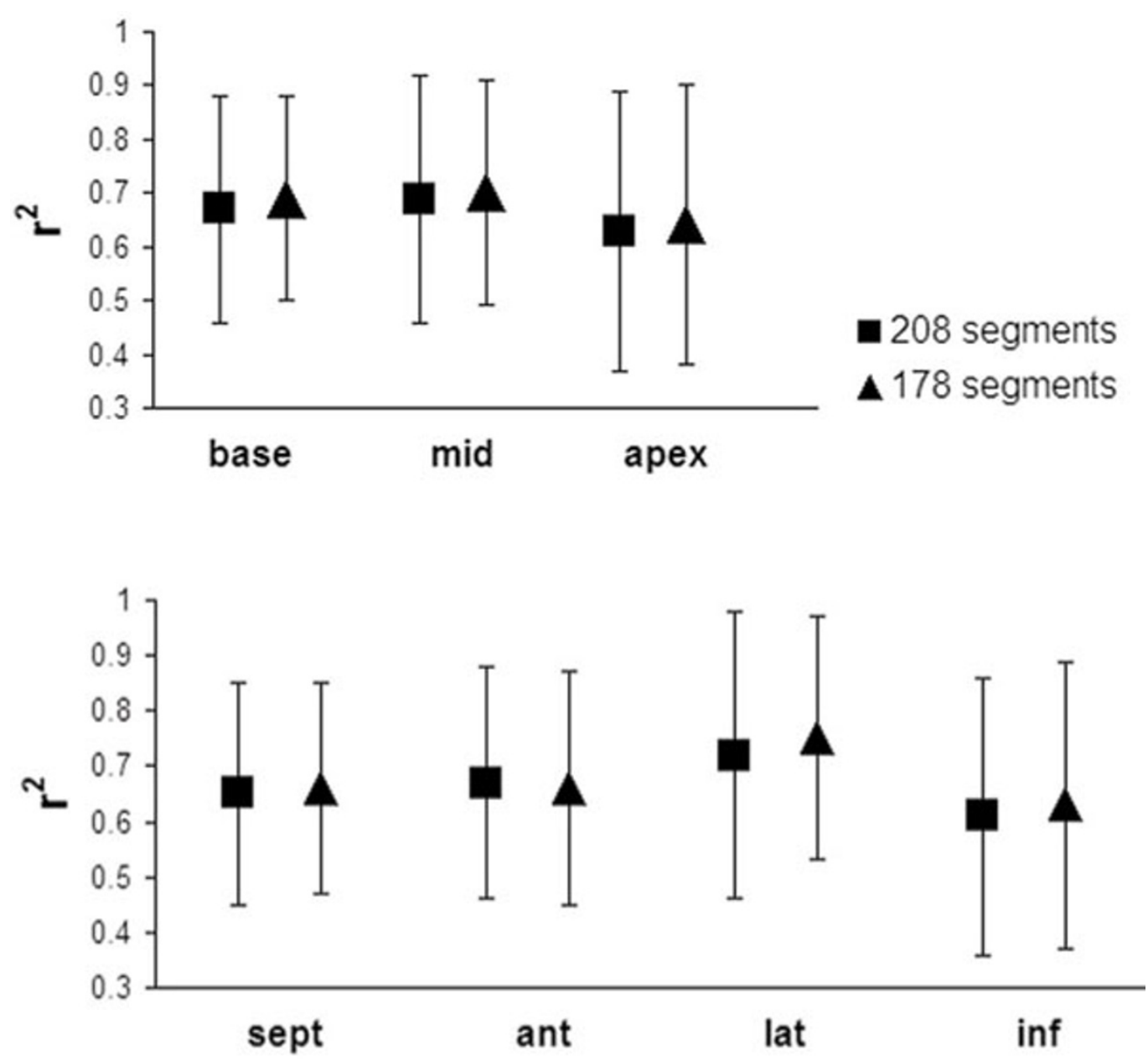

Figure I

Averaged regional $r^{2}$ values for the maximum cross-correlations of the 13 patients shown before and after exclusion of the 30 segments that did not reach a peak within the calculated time-lags. The error bars correspond to the SD.

gravity would move towards the center of the LV and no regional increase in volume will be observed. The presence of DCE did not influence the cross-correlation.

\section{Conclusion}

High correlations were observed between circumferential strain and volume curves, but regional differences in timedelay were found, especially in segments with abnormal, positive strain curves. This possibly hampers the comparison of both measures for the quantification of MD.

\section{References}

I. Am J Physiol Heart Circ Physiol 2004, 286: 1872-1880.

2. Circ 2002, 105:539-542.
Publish with Biomed Central and every scientist can read your work free of charge

"BioMed Central will be the most significant development for disseminating the results of biomedical research in our lifetime. "

Sir Paul Nurse, Cancer Research UK

Your research papers will be:

- available free of charge to the entire biomedical community

- peer reviewed and published immediately upon acceptance

- cited in PubMed and archived on PubMed Central

- yours - you keep the copyright

Submit your manuscript here:

http://www.biomedcentral.com/info/publishing_adv.asp 